\title{
Beyond the Environmental Kuznets Curve: Diffusion of Sulfur-Emissions-Abating Technology
}

\author{
DAVID I. STERN
}

The environmental Kuznets curve (EKC) has been extensively criticized on theoretical and empirical grounds. In this article, the EKC is reformulated as the best practice technology frontier-countries' distances from the frontier reflect the degree to which they have adopted the best practice technology in emissions abatement. The Kalman filter is used to model the state of sulfur emissions abatement technology in a panel of 15 mainly developed countries. The results are used to determine whether and how fast countries are converging to best practice throughout time and what variables affect the level of technology adopted. The results show that with the exception of Australia, countries are converging toward the frontier but have settled into low pollution abatement and high pollution abatement groups. Preabatement levels of pollution, income per capita, population density, and perhaps cultural factors might partly explain the level of abatement adopted.

Keywords: sulfur; emissions; production frontier; efficiency; technological change; Kalman filter; environmental Kuznets curve

$T$ he environmental Kuznets curve (EKC) model $^{1}$ has been extensively criticized on econometric grounds (Harbaugh, Levinson, \& Wilson, 2002; Koop \& Tole, 1999; Millimet, List, \& Stengos, 2003; Perman \& Stern, 2003; Stern \& Common, 2001). This article is part of an emerging literature $^{2}$, which goes beyond the environmental Kuznets curve to develop

1. See the introductory article by Heil and Leifman (2005) for a definition and survey.

2. In addition to the econometric frontier models discussed below, a number of recent decomposition studies evaluate the contributions of the major proximate factors-scale, output and input mix, and technological change-to changes in emissions using index number approaches and a variety of econometric models (Antweiler, Copeland, \& Taylor, 2001; Bruvoll, Fæhn, \& Strøm, 2003; Bruvoll \& Medin, 2003; de Bruyn, 1997; Hamilton \& Turton, 2002; Hettige, Mani, \& Wheeler, 2000; Hilton \& Levinson, 1998; Selden, Forrest, \& Lockhart, 1999; Zhang, 2000).

AUTHOR'S NOTE: I would like to thank Mark Heil, Donald Siegel, Donald Vitaliano, Larry Karp, Peter Young, three anonymous EPA reviewers, and four anonymous reviewers for Journal of Environment \& Development for useful discussions and suggestions and Lining He for research assistance. The Environmental Protection Agency provided funding under RFQ-DC-04-00027: "Economic Development and Radiatively Important Pollution."

Journal of Environment \& Development, Vol. 14, No. 1, March 2005 101-124

DOI: $10.1177 / 1070496504273512$

(C) 2005 Sage Publications 
better-specified models that model the effects of various variables, such as input and output mix, and the state of technology on the level of emissions. The focus of this article is on measuring how abatement technology diffuses across countries, which vary widely in their abatement efficiency.

In a survey of the EKC literature and its extensions, Stern (2004b) finds that although concentrations of air pollutants in urban areas do seem to follow an inverted-U-shaped path, per capita emissions of important pollutants at the national level appear to be increasing (monotonic) in income. However, changes in technology can lead with time to reductions in pollution-a lowering of the EKC - in both developing and developed countries. Case studies, particularly from China, show that pollution-reducing innovations and standards may be adopted with relatively short time lags in some developing countries (Dasgupta, Laplante, Wang, \& Wheeler, 2002; Gallagher, 2003; Jiang \& McKibbin, 2002; Wang \& Wheeler, 2003). Stern (2004b) proposes that at middle-income levels, rapid growth can overwhelm these clean-up efforts, which have more effect in slower-growing higher income countries. A new theoretical model developed by Brock and Taylor (2004) formalizes this insight.

Production frontier models ${ }^{3}$ constitute a natural framework within which to study how technology diffuses across countries. These models allow some countries to produce outputs or emit pollutants with the best practice technology, whereas other countries are operating behind the frontier using a technology that is less efficient than the best practice. Koop (1998) and Zaim and Taskin (2000) estimate global production frontier models where carbon dioxide emissions are either treated as an input (Koop, 1998) or treated as an undesirable output (Zaim \& Taskin, 2000). Stern's (2002) econometric decomposition model can be interpreted in a similar way. ${ }^{4}$

Existing modeling frameworks have, however, important limitations. Existing stochastic frontier and panel $^{5}$ regression approaches model the differences between the state of technology in each country in either a random, fixed, or deterministically changing manner. Panel approaches-fixed effects and random effects regression-allow the frontier technology to evolve stochastically with time, but all countries

3. A production frontier is a generalization of a production function to the case of multiple outputs.

4. Reinhard, Lovell, and Thijssen (1999); Fernandez, Koop, and Steel (2002); and Lansink and Silva (2003) apply similar methods at the microeconomic level to pollution from fertilizer use in agriculture.

5. A panel data set consists of time series observed for a number of individuals, firms, countries, and so forth. Panel regression methods allow for heterogeneity of some of the regression coefficients across the different individuals. 
are forced to remain a given distance from the frontier. This means that the technology is common to all countries, but each country has fixed level of inefficiency in adopting or using the technology. Stochastic frontier methods allow the distance to vary randomly, but the technology can only change deterministically. By contrast, Data Envelopment Analysis-a linear-programming technique-allows both the frontier itself and the distance from the frontier of each country to vary in every time period in an arbitrary manner. Productivity growth is then decomposed into technological change and technical efficiency change components using Malmquist index numbers (for details, see Färe, Grosskopf, Norris, \& Zhang, 1994). However, this methodology does not allow any measurement error or provide an estimate of the parameters of a production frontier that could be used to test hypotheses or forecast future emissions.

This study builds on econometric panel models to begin to model the diffusion and adoption of pollution-abating technology in a more realistic and flexible way. The Kalman filter is an algorithm for estimating complex time-series-regression-type models that, in addition to observed explanatory and dependent variables, can include unobserved time-varying state variables. I use the Kalman filter to model the state of technology in emissions abatement - a productivity indicator-in each country as an unobserved variable that evolves stochastically throughout time. The Kalman filter can estimate separate values of this unobserved technology state in each year in each country by imposing a minimally restrictive recursive structure on the dynamics through which the state of technology evolves throughout time. Such a model is equivalent to estimating a separate regression intercept term for every year in every country, which is impossible with conventional regression techniques. The evolution of the state variables can occur either independently from other countries or in association with technological change in other countries. Thus, we can test whether the abatement technology is common across countries or differs in each country, and countries can move toward or away from the frontier in complex time-dependent ways.

The model is applied to a dataset for sulfur dioxide emissions from 15 largely developed countries that have complete data. The methodology has two stages. In the first stage, a production frontier model is estimated, and inefficiencies for each country in each time period are derived. In the second stage, I carry out an exploratory analysis to determine if systematic behavior can be discerned in the inefficiencies throughout time that represents a diffusion of innovations or technological catch-up process and determine the speed of such a convergence.

The main sections of the article proceed as follows: Development of the Econometric Model and Methods, Data Sources and Characteristics and Cointegration Testing, Results and Analysis, and Discussion and Conclusion. 


\section{Development of the Econometric Model and Methods}

\section{EMISSIONS FRONTIER MODEL}

A distance function is a specialized form of production frontier model, with possibly multiple outputs and inputs, that is normalized to indicate the relative distance of the actual levels of outputs and inputs from a best practice frontier (see Färe et al., 1994; Färe, Grosskopf, Lovell, \& Pasurka, 1989). This distance is an indicator of the technical inefficiency of production. It is possible to measure that distance in any direction in the multidimensional production space. Usually, distance is measured in input or output directions as these directions conform with conventional notions of production inefficiency. Output distance measures by how much output could be increased if best practice was used, whereas input distance measures by how much inputs could be reduced to produce the same level of output. Chung, Färe, and Grosskopf (1997) introduced the measurement of distance in the direction of both desirable and undesirable outputs (pollution) but still do not measure a concept of environmental efficiency or relative efficiency in pollution abatement.

Figure 1 illustrates a distance function for measuring environmental efficiency. To keep things simple, I show only one input variable, $z{ }^{6}$ If emissions in country $i$ in year $t$ are $E 2$ and the input-output variable is $z 1$, then distance in the emissions direction is $d_{i t}=E 2 / E 1$. The best practice level of emissions is E1, which is the level of emissions for input z1 so that $\mathrm{d}=1$. $(E 1, z 1)$ is, therefore, a point on the emissions frontier $(E, z \mid d=$ 1 . The points below and to the right of the frontier are not technically feasible. Those above and to the left of the frontier are inefficient or at least not using the best practice technology. The notion implicit in this efficiency measure is that given a particular desired level of output and productivity in producing output from inputs, a particular level of inputs is required. Then, given those input requirements and productivity in the production of emissions from inputs, certain levels of emissions are implied. An alternative measure of emissions efficiency could measure efficiency of emissions production relative to both inputs and outputs. However, the decomposition into the effects of general technological change and emissions-specific technological change could not then be achieved.

Reinhard, Lovell, and Thijssen (1999) developed the first specific indicator of environmental efficiency. They compute this in an indirect way by solving the estimated production frontier for the level of the 


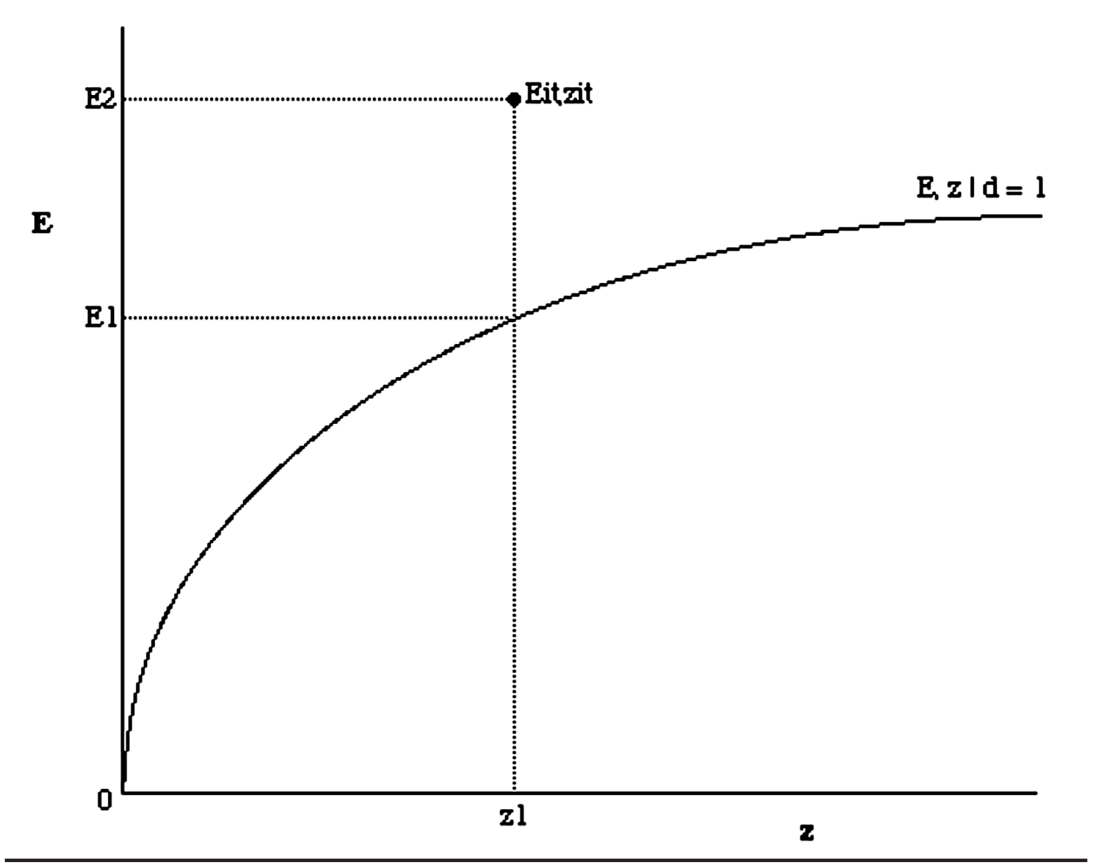

Figure 1: Emissions Frontier and Efficiency

Note: $E=$ emissions; $z=$ input variable.

undesirable input that sets the inefficiency error in the output direction to zero. Fernandez, Koop, and Steel (2002) directly estimate the level of environmental efficiency but make some separability assumptions so that they can write down separate frontiers for a function of the good outputs as a function of the inputs and for a function of the bad outputs as a function of the outputs alone. Then, they can separately define technical and environmental efficiency as the ratios of potential aggregate output to actual aggregate output in the two different separate models. The frontier estimated by Stern (2002) is a more general approach that allows direct estimation of environmental efficiency.

I assume an international emissions distance function as seen in Equation 1,

$$
f_{i t}\left(E_{i t}, \mathbf{y}_{i t}, \mathbf{x}_{i t}, A_{i t}\right)=d_{i t}
$$

where $\mathbf{y}_{i t}$ is a vector of $J$ outputs individually indexed by $j$ in country $i$ in year $t, \mathbf{x}$ is a vector of $K$ inputs individually indexed by $k, E$ is emissions, 
and $A$ represents the state of best practice-emissions-abatement technology. $d \geq 1$ is relative technical efficiency in emissions abatement. $f()$ is decreasing in $E$ and $\mathbf{x}$ and increasing in $\mathbf{y}$ and $A . f$ is homogenous of degree minus one in emissions and of degree zero in the outputs $\mathbf{y}$. This means that increasing all outputs proportionally has no effect on emissions as an increase in output holding input constant is an increase in total factor productivity (TFP). I assume that this increase in knowledge does not itself change the level of pollution. The effect of knowledge on pollution abatement is indicated by the variable $A$. Changing the mix of outputs does, however, affect the level of emissions. Changes in $A$ indicate changes in emissions that occur holding the levels and mix of inputs and outputs as well as distance constant. Total factor productivity of $\mathbf{y}$ with respect to $\mathbf{x}$ is modeled implicitly but does not need to be explicitly included as a variable in the model that is estimated.

Following Stern (2002), I specialize (Equation 1) by imposing separability of emissions and the other variables and separability between inputs $\mathbf{x}$ and outputs $\mathbf{y}$. Emissions-abating technological change is assumed to be factor and output neutral. These conditions imply that emissions can be placed on the left-hand side of the equation and all other variables (including distance) on the right-hand side (RHS). It further implies that the technological change indicator $(A)$ multiplies the entire function and does not interact with any of the variables. This means that although the level of abatement can vary across sectors, there is no difference in the rate of change in emissions abatement in the different output sectors or associated with use of the different inputs.

Andreoni and Levinson (2001) proposed that scale economies may be important in pollution abatement. Because I model abatement activity via the state of technology $(A)$, the Andreoni-Levinson proposition amounts to a correlation between the state of technology and the size of the economy. This will be tested in the second stage of the analysis. Plassmann and Khanna (2003) propose that emissions may not increase linearly in consumption, even before abatement. Larger economies can be served, for example, by larger, more efficient electric power stations, as what it appears to be happening in China recently (Zhang, 2000). Stern (2002) assumes that emissions are homogenous of degree one in the inputs, which is equivalent to constant returns to scale. We can model the Plassmann-Khanna hypothesis by allowing the degree of homogeneity of emissions in the inputs to differ from unity. ${ }^{7}$

7. Of course, the Plassmann-Khanna (2003) hypothesis is in terms of outputs and not inputs. Therefore, my approach only models the effect of scale on the sulfur emissions per unit input and does not include scale effects on the amount of input required per unit output. The latter effects are implicitly included in my indicator of total factor productivity in each country. 
I use a logarithmic or Cobb-Douglas function, which is the simplest function with desirable properties, to model the production frontier in Equation 2,

$$
\ln E_{i t}=-\ln d_{i t}^{E}+A_{t}^{E}+\sum_{k=1}^{4} y_{k} \ln y_{i t}+\gamma_{x} \ln \left(\sum_{j=1}^{11} \beta_{j} x_{j i t}\right)+u_{i t}
$$

where $d^{E}$ and $A^{E}$ are distance and the state of best practice technology in emissions abatement, respectively, and are modeled as a stochastically trending state variable using the Kalman filter. There are four output variables, $y_{k}$ : agricultural, nonmanufacturing industry, manufacturing, and services value added. $\gamma_{x}$ is the returns to scale in inputs parameter. $u_{i t}$ is a random error term representing measurement error or short-run optimization error, which may be correlated across countries. Because some inputs, such as nuclear power, oil refining, or zinc smelting, are zero in some countries in some years, a function that can accommodate zero values for some inputs is needed to introduce the inputs into the model. As in Stern (2002), I use a linear function of the inputs, which is homogenous of degree one and makes the (questionable) assumption that the inputs are infinitely substitutable for each other. The inputs $x_{j}$ are consumption of coal, oil, natural gas, hydropower, nuclear power, and biomass energy; primary smelting of copper, lead, zinc, and nickel; and oil refining (primary supply of crude oil). As emissions are homogenous in the inputs, the model is not identified, ${ }^{8}$ unless a restriction is placed on the parameters in Equation 2 or on the state of technology. I use the restriction, $\sum_{j} \beta_{j}=1$. Equation 2 is actually estimated as a group of separate time series equations, one for each country.

\section{MODELING TECHNOLOGICAL CHANGE USING THE KALMAN FILTER}

The Kalman filter is an algorithm that originated in control engineering (Kalman, 1960) for estimating unobserved time-varying state variables and that has numerous applications in modern time-series econometrics (see Hamilton, 1994; Harvey, 1989). The first step in applying the Kalman filter to an estimation problem is to reformulate the model in question in terms of a state-space model. A state-space model includes both a system of regression equations as in Equation 2-known as the measurement equations - and a second system of equations - known as the transition equations-which model the evolution of the unobserved

8. A nonidentifiable econometric model is one that cannot be estimated, as more than one set of parameter estimates are compatible with the same error terms. Identification ensures that there is a unique vector of regression coefficients. 
state variables. The transition equations are very similar in form to regression equations for autoregressive time-series models; but instead of regressing observed variables on their lagged values, the unobserved variables are modeled as a function of their past values, possibly other variables, and random errors. The values of the state variables are constrained because they appear in both the measurement equations, which involve observed variables, and the transition equations.

In the Kalman filter approach to modeling technological change, either simple random walks (I[1] processes) with or without drift, integrated random walks (I[2] processes), or local linear trends (integrated random walks with noise), which can show very varied behavior, are typically used to represent the state of technology (Harvey \& Marshall, 1991). In the simple random walk case actually used in this article, the transition equations are as seen in Equation 3:

$$
\mathbf{a}_{i t+1=} \mathbf{a}_{i t}+\eta_{i t}
$$

where $\eta_{t}$ is a random error process and $\mathbf{a}_{i t}$ is the vector of stochastic trend(s). As in the case of the measurement errors, the error term in Equation 3 can be correlated across countries. If there were no correlation across countries, then technology would evolve completely independently in every country. Convergence of technology across countries requires that the state variables representing the state of technology in each country cointegrate with each other. ${ }^{9}$ For this to occur, none of the random shock variables can be completely independent of all the others, which can be tested by examining the covariance matrix of the shocks. This is similar to Strazicich and List's (2003) time-series approach, although they test for cointegration using conventional autoregressive unit root tests and for the convergence of carbon emissions rather than a convergence of technology.

To achieve identification, the total number of stochastic trends that enter the measurement equations independently cannot exceed the number of measurement equations. Obviously, we cannot then estimate a technological change and an efficiency trend separately in each country. If we knew which country was the technology leader a priori, then

9. Cointegration occurs when variables that contain random-walk components or stochastic trends share these components so that some weighted sum of the variables does not contain a random walk. If this does not occur, then a regression using these variables will end up with a random walk in the residual term, which violates the classical regression assumptions and invalidates any inference based on the regression results. If a group of variables cointegrate, despite each following a random walk, then the group will tend to move together, and, following shocks that push the variables apart, they will tend to converge with each other again. 
we could model the trend in that country as the trend in pure technical progress and introduce this trend, plus a catch-up trend in each country. However, in general, the best we can achieve is to allow the state of technology to evolve separately in each country but to allow innovations to these trends to be correlated. Decomposition into the two components is achieved subsequent to estimation and $a_{i t}=-\ln d_{i t}^{E}+\ln A_{t}^{E}$.

The Kalman filter estimates time series for each of the state variables, given the values of the covariance matrices of the shocks in the measurement and transition equations and the parameters $\gamma$ and $\beta$ in the frontier model, which are known collectively as hyperparameters. The filter is also used to compute the prediction error decomposition of the likelihood function in parallel with the state vector. This likelihood function in maximized using the Broyden, Fletcher, Goldfarb, and Shanno (BFGS) nonlinear optimization algorithm to find the maximum likelihood values of the hyperparameters. Given maximum likelihood estimates of the hyperparameters, the Kalman filter produces maximum likelihood estimates of the state variables using only data for previous periods. Given these estimates, a smoother algorithm is used to calculate values for the unobserved state variables utilizing the entire dataset. The initial state can be estimated using the diffuse Kalman filter framework (De Jong, 1991a, 1991b).

\section{CONVERGENCE AND DIFFUSION ANALYSIS}

Convergence to the best practice frontier can be tested in a variety of ways. First, we can check that the estimated state variable covariance matrix has reduced rank, which indicates that the technology trends cointegrate. Without cointegration, convergence is impossible. But it does not necessarily mean that convergence will occur within the period under consideration. Second, as in the traditional growth literature, we can test whether there is negative correlation between initial income levels and the growth rate of efficiency to see if efficiency rose faster in poorer countries. These two approaches are broadly similar to Strazicich and List's (2003) time-series and cross-sectional tests for convergence, respectively. Finally, the simplest convergence test of all is just to check whether efficiencies are increasing throughout time, so that countries are on average approaching the frontier. I also look at the variance of efficiency throughout time.

It is important also to look at the relations between the efficiency component and the level of adopted technology and a variety of variables, such as gross domestic product (GDP) per capita, size of the economy, and population density, that might be believed to influence environmental policy according to the environmental Kuznets curve literature. The 
first of these is just the standard EKC effect on abatement ${ }^{10}$-is the level of abatement correlated with the level of income per capita? The second is the Andreoni and Levinson (2001) proposal that abatement will be greater in a larger economy. The third expresses the idea that with higher population densities, more people will be affected by a given amount of pollution and hence more abatement would optimally be undertaken.

Another hypothesis is that high levels of pollution result in action to reduce that pollution, so that countries with high levels of emissions per unit area are aggressive in adopting pollution-abating technology. This would explain why Australia appears to be taking little action against pollution and why China seems to be acting relatively early, given its income level, to adopt Western standards. The problem with this is that obviously pollution emissions are an endogenous variable partly determined by the state of technology. But, actually, the relevant variable is what the level of pollution would be in the absence of abatement. The higher this untreated level of emissions per unit area would be, the more aggressive policy and voluntary action geared to abatement will be. The $\log$ of the unabated level is equal to the log of observed emissions minus the logarithmic state variable.

A notion of the rate of diffusion can be gained by seeing, given the rate of technical progress and the average rate of efficiency change in each country, how long it will take each country to reach the state of technology in the current technology leader. It is not possible to estimate a diffusion curve for a specific technological shock.

\section{Data Sources and Characteristics and Cointegration Testing}

The appendix ${ }^{11}$ gives details of the data sources. I assembled a panel dataset for sulfur emissions and the explanatory variables for the period from 1971 to 2000 . Only 16 countries had complete data on all variables in all years. ${ }^{12}$ Because of the slowness of estimation of high dimension

10. I assume that the environmental Kuznets curve (EKC) theory is that abatement is low in low-income countries and increases monotonically with income. Eventually, the abatement effect, together with the composition, is supposed to overwhelm the scale effect. In the EKC theory, income is also supposed to have a nonmonotonic effect on the composition effect.

11. Supplemental data may be found online at http://jed.sagepub.com/content/ vol14/issue1/.

12. Sulfur emissions data are not available for the 1990s for the Middle East, Africa, and Latin America. However, since carrying out the analysis, I have located data for Mexico. Data are available for 1991 to 1997 and 2000 for East and South Asian countries. Missing data on economic structure caused me to drop Canada and some European countries. Incomplete economic data led me to drop other countries, particularly in Eastern Europe. 
models of this type, I decided to estimate a model for the 16 countries with complete observations on all variables: Australia, Austria, Belgium, Denmark, Finland, France, Germany, Greece, Italy, Japan, Luxembourg, Netherlands, Portugal, Spain, the United Kingdom, and the United States.

The results showed that for much of the period, Luxembourg was on the efficient frontier and strongly influenced the results on convergence. Luxembourg is the smallest economy in the data set and also a very energy and coal intensive economy. It has some of the highest per capita carbon emissions in the world. Additionally, it has by far the highest GDP per capita in the data set. The covariance between these variables could result in biased estimation. It is also possible that emissions are underreported. In 1971, its sulfur emissions per tonne of carbon were some of the lowest of any year and any country. Therefore, I dropped Luxembourg from the data set and estimated the model using the remaining 15 countries.

The remaining data span small economies, such as Finland ( 54 billion 1995 PPP U.S. dollars in 1971), to the world's largest economy, the United States (\$9.2 trillion in 2000), and there is a good range of sizes in between. This should help in estimating the returns to scale parameter. Income per capita levels vary from $\$ 6,745$ (Portugal in 1971) to $\$ 33,293$ (United States in 2000). The former is less than Mexico today. Sulfur emissions per capita vary from $2.3 \mathrm{~kg}$ (Austria in 2000) to $68 \mathrm{~kg}$ (United States in 1973) per year. Population density varies from 1.68 (Australia in 1971) to 383 people per square kilometer (Netherlands, 2000). Economies also vary substantially in terms of energy mix, metal smelting, and, to some degree, output structure, although there are no true agrarian economies in the sample, as the lowest income level is above the global average. Stern and Common (2001) found that using nonrandom samples in the context of an inadequate statistical model, such as the EKC, leads to bias. In the present case, although it would be desirable to include data from poorer countries, the bias should be less as the model is statistically more adequate, and problems caused by omitted variables bias are likely to not be as severe. However, we do not know a priori how well the model would perform as an explanation of developments in less developed countries (LDCs).

Panel data sets of this type are likely to exhibit stochastic trends or random walk components in the data (see Stern, 2004b). Perman and Stern (2003) employ some recently developed tests for random walks, or so-called unit roots, in panel data and find that sulfur emissions and GDP per capita may contain a unit root. The unit root hypothesis could be rejected for sulfur (but not GDP) using the Im, Pesaran, and Shin (2003) test when the alternative was trend stationarity. But Perman and Stern (2003) found that alternative hypotheses and tests result in acceptance of the unit root hypothesis for sulfur too. Heil and Selden (1999) 
and Coondoo and Dinda (2002) find unit roots for carbon dioxide emissions and GDP in panel data. de Bruyn (2000) and Day and Grafton (2003) carry out time-series unit root tests for the Netherlands, the United Kingdom, the United States, West Germany, and Canada for a variety of pollutants with very similar results. Furthermore, the technical change trends in the model in this article are random walks by construction. Thus, we can conclude that as unit roots are present in some of the variables and possibly in all of them, cointegration testing is required.

Pedroni (1997) derives an appropriate test of cointegration in panel data under the assumption that the regressors are exogenous and there is a single cointegrating vector, which is appropriate in our case. When there is a single cointegrating vector, panel estimates of the regression parameters are consistent even in the face of noncointegration, although they can show small sample bias. The convergence rate is proportional to $\sqrt{N}$ (Kao, 1999; Pedroni, 1997). But very large cross-sectional samples are probably needed before we can safely ignore the cointegration issue. In any case, under noncointegration, the estimate converges to zero, even if some RHS variables are related to the dependent variable and the $t$ statistics of the parameters diverge. These results do not hold if slope heterogeneity is allowed. The result does allow the constant in the cointegrating relation to vary across countries. The following test statistic (Equation 4) is particularly easy to construct:

$$
T \sqrt{N / 2}\left(\hat{\rho}_{N T}-1\right)=T \sqrt{N / 2}\left(\sum_{i=1}^{N} \sum_{t=1}^{T} e_{i t-1}^{2}\right)^{-1} \sum_{i=1}^{N} \sum_{t=1}^{T} e_{i t-1}^{2} \Delta e_{i t} \rightarrow N(0,1) .
$$

This version of the test does not require any auxiliary regressions but does not include a correction for higher order serial correlation. It assumes that the autoregressive parameter is equal across all countries.

\section{Results and Analysis}

\section{ECONOMETRIC RESULTS}

As it was not practical to estimate multiple versions of the model for 15 or 16 country samples, Stern (2004a) estimates several versions of the model for five countries-Australia, France, Germany, the United Kingdom, and the United States - to find the appropriate form of the model. The model with the highest Akaike information criterion was found to have I(1) technology trends with constant drift terms, correlated state variable shocks, and heteroskedastic but independent measurement errors. I chose to restrict the drift term to zero in the 15-country model to 
Table 1

Country-Specific Statistics

\begin{tabular}{lcccc}
\hline & $\begin{array}{c}\text { Standard } \\
\text { Error of } \\
\text { the Residuals }\end{array}$ & $\begin{array}{c}\text { Significance } \\
\text { of } \\
Q(1)\end{array}$ & $\begin{array}{c}\text { Significance } \\
\text { of } \\
Q(7)\end{array}$ & $\begin{array}{c}\text { Average Number } \\
\text { of Years } \\
\text { From Frontier }\end{array}$ \\
\hline Australia & 0.1133 & 0.0850 & 0.3255 & $\infty$ \\
Austria & 0.0043 & 0.1983 & 0.2497 & 8 \\
Belgium & 0.1289 & 0.0023 & 0.0496 & 16 \\
Denmark & 0.2820 & 0.7404 & 0.1351 & 8 \\
Finland & 0.2420 & 0.9904 & 0.2741 & 12 \\
France & 0.1290 & 0.1092 & 0.2427 & 54 \\
Germany & 0.0060 & 0.1685 & 0.0303 & 21 \\
Greece & 0.1951 & 0.0599 & 0.2609 & $\infty$ \\
Italy & 0.0022 & 0.1070 & 0.1837 & 36 \\
Japan & 0.0135 & 0.0043 & 0.0068 & 2 \\
Netherlands & 0.1850 & 0.8134 & 0.0000 & 7 \\
Portugal & 0.2184 & 0.0151 & 0.0000 & 30802 \\
Spain & 0.1510 & 0.0032 & 0.0017 & 67 \\
United Kingdom & 0.1855 & 0.3511 & 0.2946 & 54 \\
United States & 0.0072 & 0.0509 & 0.0096 & 63 \\
\hline
\end{tabular}

reduce the number of parameters to be estimated and simplify the test of convergence to be one of just the correlation between the shocks to the state variables.

Table 1 presents the significance level of the $Q(1)$ and $Q(7)$ statistics, which test first-order serial correlation of the residuals and higher order serial correlation up to seven lags, respectively. The picture is a little mixed. The tests show that the residuals for Belgium and Spain show first-order serial correlation that is significant at the $1 \%$ level. Several countries have significant higher order serial correlation. Therefore, the reported standard errors for the model parameters could indicate higher precision of estimation than is actually the case. These results indicate that the model might benefit from either an I(2) specification of the trends or more sophisticated estimation techniques, neither of which has been attempted.

However, the Pedroni (1997) statistic (4) adjusted to have a standard normal distribution is -93.97 , which clearly rejects the null of no cointegration. Even if higher order serial correlation in the residuals affects the statistic, this statistic is so large in absolute value to leave no doubt that cointegration is achieved. Of course, given the stochastic trends included in the model, the possibility that the model would not cointegrate is remote. 
Table 2

Frontier Parameter Estimates

\begin{tabular}{|c|c|c|c|}
\hline Variable & Coefficients & SE & t Statistic \\
\hline \multicolumn{4}{|l|}{ Coefficients of sulfur WRT fuels } \\
\hline Coal & 0.0607 & 0.0104 & 5.83 \\
\hline Oil & 0.0337 & 2.65E-03 & 12.70 \\
\hline Natural gas & -0.0173 & 3.15E-03 & -5.48 \\
\hline Hydro & -0.0615 & 0.0159 & -3.87 \\
\hline Nuclear & -0.0157 & $1.61 \mathrm{E}-03$ & -9.78 \\
\hline Biomass & 0.0187 & 0.0194 & 1.70 \\
\hline \multicolumn{4}{|l|}{$\begin{array}{l}\text { Coefficients of sulfur WRT other } \\
\text { commodity production }\end{array}$} \\
\hline Oil refining & 0.0081 & 8.43E-04 & 9.60 \\
\hline Copper & 0.7730 & 0.1154 & 6.69 \\
\hline Zinc & 0.2516 & 0.1417 & 1.77 \\
\hline Lead & 0.3720 & 0.6666 & 0.56 \\
\hline Nickel & -0.4231 & NA & NA \\
\hline \multicolumn{4}{|l|}{ Output elasticities of sulfur } \\
\hline \multicolumn{4}{|l|}{ WRT to industries } \\
\hline Agriculture & 0.0092 & NA & NA \\
\hline Nonmanufacturing industry & 0.0050 & 0.0194 & 0.28 \\
\hline Manufacturing & 0.0022 & 0.0516 & 0.03 \\
\hline Services & -0.0164 & 0.0498 & -0.32 \\
\hline Returns to scale in inputs & 0.7678 & 0.0310 & 24.79 \\
\hline
\end{tabular}

Note: $\mathrm{WRT}=$ with respect to.

The standard errors of each country's residuals series are also given in Table 1 . These have a 0.66 correlation with the reciprocal of the mean square root of population in each country, which are the weights used by Stern (2002) to accommodate the effects of grouping heteroskedasticity. This indicates that grouping heteroskedasticity is important and that this model can accommodate it. Future modeling efforts could impose such a structure on the error covariance matrix to reduce the number of parameters to be estimated.

Table 2 presents estimates of the frontier parameters and tests of their significance. The values of the coefficients are mostly close to expectations. Coefficients are estimated relative to the sample mean effects, so that a negative coefficient means that increasing that input, ceteris paribus, lowers emissions relative to the sample mean. The coefficients on fuels and other commodities have also been normalized to sum to unity, and this, together with the nonconstant returns to scale, means that we cannot directly interpret the coefficients in an absolute sense. Among the fuels, coal has the highest coefficient, followed by oil, biomass, natural gas, and the two forms of primary electricity. This ordering is expected 
and similar to that in Stern (2002). Among the other commodities, copper and zinc have the two greatest significant coefficients. The relatively small but significant coefficient on oil refining is surprising. None of the industry coefficients is significantly different from zero. This could imply either that controlling for fuel mix, metal smelting, and oil refining, abatement is relatively stronger in the industries that would be expected to have higher emissions before abatement, or that the patterns of emissions by industry vary too much across the sample to result in significant effects in the sample as a whole. ${ }^{13}$

The returns-to-scale parameter is significantly less than unity, confirming the Plassmann-Khanna (2003) hypothesis. Increasing returns to scale were also found for all of the five country models.

Figure 2 presents the antilogarithms of the state variables for each country and time period. As explained above, these states are the actual level of emissions-specific technology in each country and include both the effects of changes in best practice and the relative levels of efficiency or adoption in each country. With the singular exception of Australia, a general downward trend, showing a ceteris paribus reduction in sulfur emissions, is apparent. Portugal starts the period as the cleanest country all things considered. Japan sees a rapid improvement in the first few years and forms the best practice frontier from 1973 to 1990. From 1990 to 1999, Austria is on the best practice frontier. Denmark becomes the cleanest country in 2000. United States starts the period as the dirtiest economy and ends it slightly better than Australia, which is now the dirtiest economy in the sample.

The initial scatter of countries sorts out into two clear groups by the end of the period. The low pollution group consists of Austria, Belgium, Denmark, Finland, Germany, Japan, and the Netherlands. None of these names is a surprise as countries that might be pursuing a more stringent environmental policy. The higher pollution group consists of Australia, France, Greece, Italy, Portugal, Spain, the United Kingdom, and the United States. With the exception of Germany and Japan, the larger economies are in this second group as are the two poorest economies.

That Australia shows no apparent convergence with the other countries is also no surprise, given the remoteness of its location, its low population density, and its government's policy as expressed, for example, in its negotiation of an increase in carbon emissions at Kyoto and tendency since then to follow the U.S. line on climate policy. Also of interest is Germany, which was a member of the higher polluting group until 1987 and, similar to Australia, was moving to higher emissions. Then, Germany made a very rapid move in the opposite direction, following the Long Range Transportation of Atmospheric Pollution (LRTAP) 


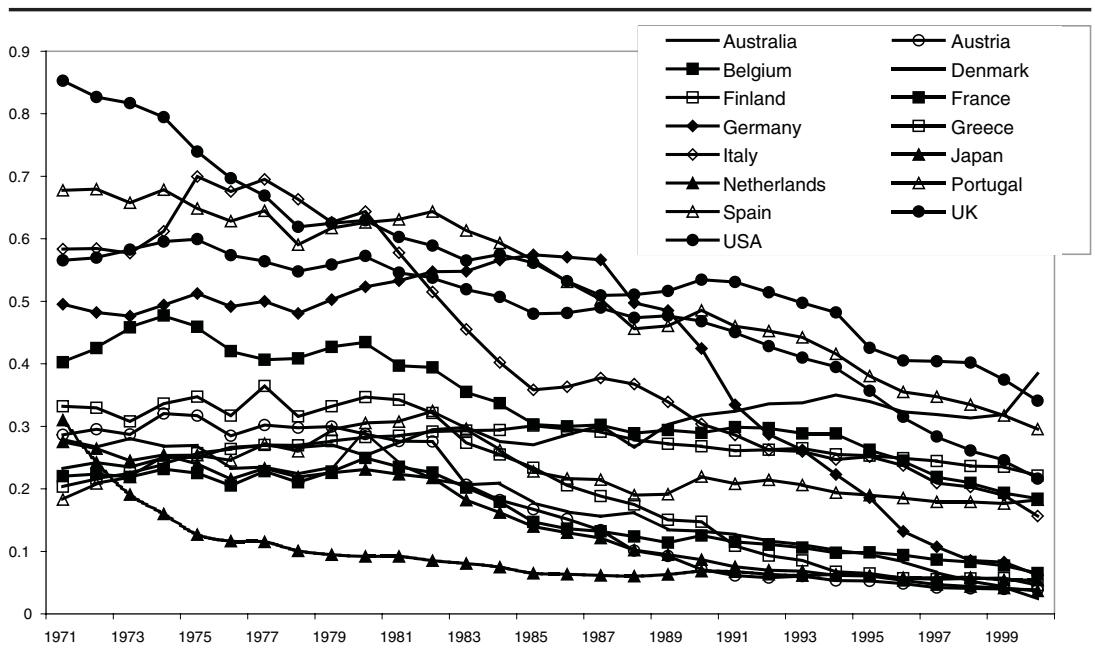

Figure 2: Emissions Technology Trends

Note: The $y$-axis indicates the state of technology. The figures are a unitless index.

agreement and, subsequently, reunification to join the low pollution group. Japan cut emissions dramatically in the early 1970s. This period followed various environmental catastrophes in Japan, such as the Minamata mercury poisoning and asthma because of sulfur dioxide emissions that resulted from the very rapid postwar economic growth. Environmental policy regarding air and water pollution was first introduced in this period (Ziegler, 1995). This suggests that unhealthily high levels of pollution result in action being taken regardless of the state of development in an economy. ${ }^{14}$ On the other hand, France shows slowly improving technology and belongs to the high-polluting group. With its strong emphasis on nuclear power and relatively small tradition of heavy industry compared to some other developed countries, preabatement levels of pollution are lower than in some other countries. Thus, there may be less emphasis on reducing pollution further. Other factors affecting technology adoption may be more abstract, such as possible cultural factors that keep pollution levels higher in English- and Latin-speaking countries. For example, it is well known that the initial United Kingdom government action under the LRTAP agreement was minimal compared with other European countries (Levy, 1994). These patterns are explored in a quantitative manner in the Diffusion Analysis section below.

14. I am not suggesting that the same action will be taken in every country in reaction to a given level of pollution. The potential level of pollution is one factor in a multifactor model that would explain policy stringency. 


\section{CONVERGENCE}

In this section, I examine the evidence for emissions-specific technological convergence across countries. As explained above, convergence in technology is only possible if the covariance matrix $\operatorname{VAR}(\eta)$ is reduced rank. This can be determined from the eigenvalues of $\operatorname{VAR}(\eta)$. This is the first necessary condition for potential convergence; the second is to determine that none of the countries has an idiosyncratic shock not shared by any of the other countries. During the estimation procedure, it became apparent that the number of nonzero eigenvalues of VAR $(\eta)$ was at most nine. This restriction was then imposed in the final estimation iterations as it saves on nonlinear estimation of 21 parameters. Therefore, I can conclude that $\mathrm{H}$ is reduced rank.

The second necessary condition is that there are no idiosyncratic shocks that are not shared by another country. Actually this condition implies the first. Based on the estimated $t$ statistics (not presented in this article), all but one of the columns of the Choleski decomposition of $\operatorname{VAR}(\eta)$ have two or more significant parameters at the $5 \%$ level. At the $10 \%$ level, all have at least two significant parameters. Therefore, there are no idiosyncratic shocks that are not shared by any other countries. However, many of these correlations are negative, particularly between Australia and the other countries and so these results are hard to interpret. Further tests are needed to determine if convergence occurred during the 30-year sample period.

Figure 3 shows the trends in distance from the best practice frontier in each country throughout time. The trends seem to divide into four subperiods. In the period from 1971 to 1972, all countries appear to converge though this probably is an artifact of the upward move in Portugal's state of technology during this period. From then until around 1982, with the exception of Japan, most countries appear to drift away from the frontier. From then until the late 1990s, the low pollution group emerges and converges on the frontier, whereas the high pollution group increases its distance. Finally, in 2000, all countries apart from Denmark diverge strongly from the frontier. This is an artifact of the fall in the technology state in Denmark that year. Relative to Japan and Austria, there is little divergence in the final year.

Examination of the statistical behavior of distance with time shows some evidence of divergence during the 28 years from 1972 with a slowly increasing mean and variance (see Figures 4 and 5). ${ }^{15}$ Each country, on average, maintained its average efficiency level relative to best practice from the mid-1980s to 1999; thus, there has not been convergence in relative terms. However, the state of technology cannot decline

15. Supplemental data may be found online at http://jed.sagepub.com/content/ vol14/issue1/. 


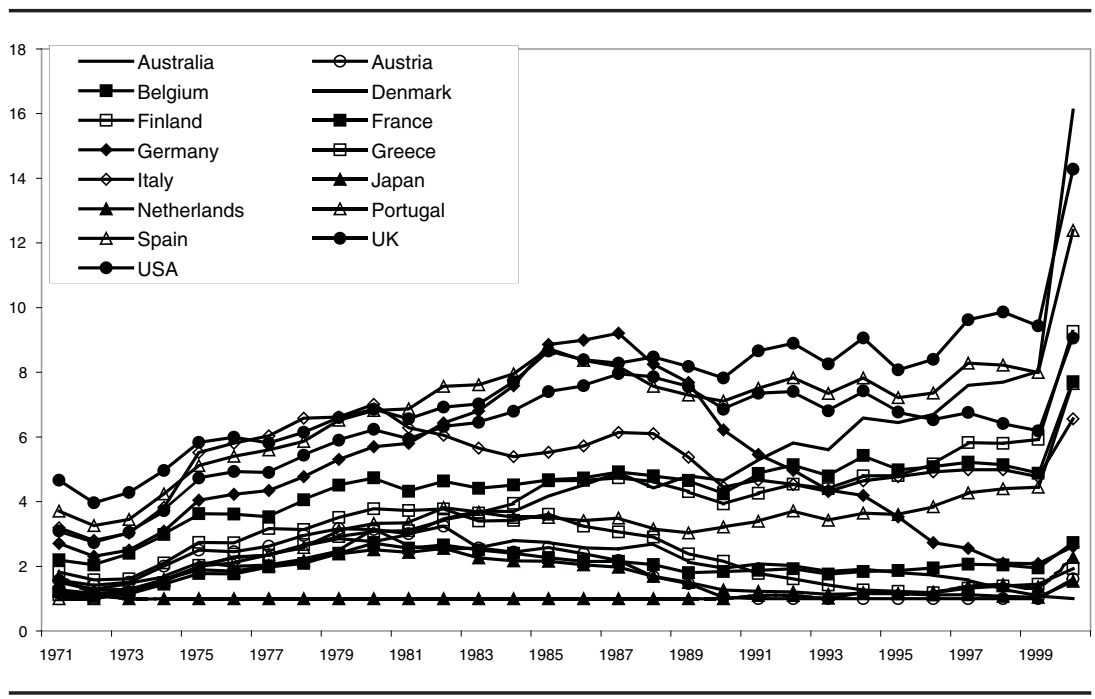

Figure 3: Emissions Distance Trends

Note: The $y$-axis gives the distance of the state of technology in each country from the best practice frontier. Adistance of one indicates that the country is on the best practice frontier.

below zero emissions, and, therefore, if the trend is down in most countries, technology will converge in terms of levels, though not necessarily in terms of logarithms, which depends on the relative distance. Examination of the mean of the state of technology and its variance shows convergence on that basis.

Finally, I carry out the traditional test of convergence from the growth literature, which asks whether there is a correlation between the rate of technological change and initial income. The correlation between 1971 income and the mean log first difference of the technology state variable is -0.33 , rising to -0.38 for $\log$ initial income. The $t$ statistics are only -1.27 and -1.50 . Thus, although the relationship has the expected sign, the association is not that strong.

\section{DIFFUSION ANALYSIS}

In this section, I compute correlations between the state of absolute and relative technology and possibly relevant variables that affect the adoption of technology as described above. Then, I compute the time it takes for technology to diffuse from leader to follower countries.

I computed the correlation matrix between the logarithms of the state variable and distance and the logs of GDP per capita $(\operatorname{lnGDP} / \mathrm{P})$, total GDP, population density $(\ln \mathrm{P} / \mathrm{A})$, and preabatement emissions per square kilometer $\left(\ln \mathrm{S}^{*} / \mathrm{A}\right)$, which are tests of the four hypotheses discussed in the Modeling Technological Change Using the Kalman Filter 
Table 3

Correlation Matrix

\begin{tabular}{lrrrrrr}
\hline & $\ln D I S T A N C E$ & $\ln S T A T E$ & $\ln G D P / P$ & $\ln G D P$ & $\ln P / A$ & $\ln S^{*} / A$ \\
\hline $\ln$ IISTANCE & 1.000 & & & & & \\
$\ln S T A T E$ & 0.751 & 1.000 & & & & \\
$\operatorname{lnGDP} / \mathrm{P}$ & 0.059 & -0.363 & 1.000 & & & \\
$\ln \mathrm{nDP}$ & 0.406 & 0.262 & 0.456 & 1.000 & & \\
$\ln \mathrm{P} / \mathrm{A}$ & -0.213 & -0.216 & -0.088 & 0.136 & 1.000 & \\
$\ln S^{*} / \mathrm{A}$ & -0.308 & -0.287 & -0.016 & -0.011 & 0.942 & 1.000 \\
\hline
\end{tabular}

section above: the EKC effect on technology, the Andreoni-Levinson (2001) hypothesis, the population density effect, and the pollution concentration effect. These are presented in Table 3. All the correlations between $\ln$ Distance and $\ln S$ tate and the other variables are nominally highly significant apart from the relation between $\ln$ Distance and lnGDP per capita. The relation of GDP per capita with the state of technology does have the expected sign; higher income leads to adoption of lower emissions technology. The correlations with total GDP are positive, which contradicts the Andreoni-Levinson hypothesis that larger economies have an economy of scale in abatement and hence are likely to show higher levels of abatement. The correlations with population density and unabated emissions per unit area are all negative as expected. Higher pollution concentrations and greater numbers of affected people are associated with more abatement. But these two variables are strongly correlated with each other, and it would be difficult to distinguish their effects.

Table 1 also presents the average distance of each country from the frontier technology in terms of years. This is computed as follows: How many years will it take the country to reach the level of technology in today's technology leader at the average logarithmic rate of change of the state variable in that country during the entire 30-year period. This distance was then averaged for each country during the 30-year period. Australia and Greece are an infinite time from the frontier because their average rate of technological change is positive rather than negative. Portugal is also an effectively infinite time from the frontier. Japan is on average closest, but the United States is far by this measure. So there is no simple relationship between income level and the rate of diffusion. Instead the countries are differentiated again by membership in the low pollution and high pollution groups. The population weighted mean for the low pollution group is 10 years, whereas the weighted mean for the high pollution group (dropping Australia, Greece, and Portugal) is 58 years. 


\section{Discussion and Conclusion}

This article has presented an approach to measuring environmental efficiency and demonstrated that the Kalman filter is a viable method for estimating technological change in panel data that produces plausible results. However, the dimension of such models has to be fairly small for reasonable estimation times on personal computers. I have also tested a number of key hypotheses from the environmental Kuznets curve and growth literature using a data set for sulfur emissions in 15 mostly developed countries for a 3-decade period. On a methodological level, the article makes the following original contributions:

1. The production frontier is manipulated to measure environmental (emissions) efficiency directly. Previous studies either estimate it indirectly or make special assumptions regarding separability.

2. I model technological change using the Kalman filter, which has not previously been done using panel data.

3. I estimate the inefficiency components using the Kalman filter too. This has not been done before. This imposes far fewer restrictions on the diffusion of technology across countries than imposed by previous econometric approaches.

In a departure from Stern (2002), I found no significant effect of industry mix on emissions. I found that the elasticity of emissions, with respect to aggregate inputs, was less than unity, which supports the Plassmann-Khanna (2003) hypothesis that there are pre-abatement economies of scale. An exploratory analysis does not support the Andreoni-Levinson (2001) hypothesis that there are economies of scale in abatement so that larger economies would have lower emissions, ceteris paribus. There was some support that higher income per capita, higher population density, and higher potential preabatement emissions are associated with a higher level of abatement technology. The latter two factors combined with the finding on the Plassmann-Khanna hypothesis might explain the recent moves in China to address pollution problems discussed in the beginning of the article. However, income per capita did not explain distance from the frontier or the rate of convergence on the frontier.

However, the countries included in this study have, throughout time, sorted out into two groups: a high pollution group and a low pollution group, consisting of Japan and Germanic and Scandinavian countries that have adopted a much higher level of technology. Anglo-Saxon and Latin or Mediterranean countries seem less concerned with pollution; the United Kingdom and the United States are in the high-polluting group, whereas Australia is diverging from all the other countries and seeing a somewhat declining level of abatement technology. All coun- 
tries but Australia, Portugal, and Greece are converging toward the best practice frontier, but the other members of the high-polluting group are converging very slowly. Convergence is not very strong overall; the average distance from the frontier is maintained throughout time, and the relation between initial income and the rate of technological change has the expected sign but high variance. My previous research (Stern \& Common, 2001) has shown that there is also such technological change in developing countries but perhaps at a slower rate than in the average developed country. As I find a variety of rates of emissions-abatementspecific technological change across countries in this article, we might also expect this rate to vary dramatically across the developing world too.

The results show that technology does not evolve independently in each country, but neither is it a question of adopting different amounts of the same technology in all countries. The estimation identified up to nine separate components of technological change that appear in different mixes in different countries.

A limitation of this study is that only 30 years of data from 15 mostly developed countries was used to estimate the model. As mentioned in the Data Sources and Characteristics and Cointegration Testing section, this could introduce bias. We do not know a priori how well the model would perform as an explanation of developments in LDCs. As the model appears to be more statistically adequate than EKC models, this bias might be expected to be less than in the case of EKC models estimated with nonrandom samples. Equally important may be the fact that the sample only covers a recent 30 -year period. Understanding the longterm evolution of the economy, resource use, and environmental impacts may require analysis of very-long-term time series spanning centuries (Kander \& Lindmark, in press). In a qualitative sense, the results of this study seem intuitively reasonable in the light of my past research, but we should not place too much confidence in the exact quantitative results.

The analysis could be extended by carrying out a decomposition of emissions as performed by Stern (2002). The results in this article suggest that emissions-specific technological change will dominate all other effects to a greater extent than shown by that previous study. Applying more sophisticated estimation procedures to address the remaining residual serial correlation issue may be too computationally expensive at present, but should be explored.

Application of the method to other pollutants will differ depending on the pollutant in question. For example, there is no abatement technology for carbon dioxide emissions apart from fuel switching and improvements in energy efficiency. Therefore, there is no need to use the Kalman filter to model the state of an unobserved abatement technology. The state of technology in this model is defined by the relation between 
inputs and good outputs in analogy to what I referred to as TFP in the sulfur model in this article. The model would relate carbon emissions directly in an unchanging parametric fashion to the inputs. Nonlinear regression should be sufficient for estimating such a model, and much larger numbers of countries can be included at low computational cost.

\section{References}

ASL \& Associates. (1997). Sulfur emissions by country and year (Report No. DE96014790). Washington, DC: U.S. Department of Energy.

Andreoni, J., \& Levinson, A. (2001). The simple analytics of the environmental Kuznets curve. Journal of Public Economics, 80, 269-286.

Antweiler W., Copeland, B. R., \& Taylor, M. S. (2001). Is free trade good for the environment? American Economic Review, 91, 877-908.

Australian Greenhouse Office. (2002). National greenhouse gas inventory: 2000 inventory. Canberra: Commonwealth of Australia.

Brock, W. A., \& Taylor, M. S. (2004). The green Solow model (Working Paper No. 2004-16). Madison: University of Wisconsin, Department of Economics.

Bruvoll A., Fæhn, T., \& Strøm, B. (2003). Quantifying central hypotheses on environmental Kuznets curves for a rich economy: A computable general equilibrium study. Scottish Journal of Political Economy, 50(2), 149-173.

Bruvoll, A., \& Medin, H. (2003). Factors behind the environmental Kuznets curve: A decomposition of the changes in air pollution. Environmental \& Resource Economics, 24, 27-48.

Chung, Y. H., Färe, R., \& Grosskopf, S. (1997). Productivity and undesirable outputs: A directional distance function approach. Journal of Environmental Management, 51(3), 229240.

Coondoo, D., \& Dinda, S. (2002) Causality between income and emission: A country groupspecific econometric analysis. Ecological Economics, 40, 351-367.

Dasgupta, S., Laplante, B., Wang, H., \& Wheeler, D. (2002). Confronting the environmental Kuznets curve. Journal of Economic Perspectives, 16, 147-168.

Day, K. M., \& Grafton, R. Q. (2003). Growth and the environment in Canada: An empirical analysis. Canadian Journal of Agricultural Economics, 51, 197-216.

de Bruyn, S. M. (1997). Explaining the environmental Kuznets curve: Structural change and international agreements in reducing sulphur emissions. Environment \& Development Economics, 2, 485-503.

de Bruyn, S. M. (2000). Economic growth and the environment: An empirical analysis. Dordrecht, the Netherlands: Kluwer Academic.

De Jong, P. (1991a). The diffuse Kalman filter. Annals of Statistics, 19, 1073-1083.

De Jong, P. (1991b). Stable algorithms for the state space model. Journal of Time Series Analysis, 12(2), 143-157.

Environmental Protection Agency. (2000). National air pollutant emissions trends 1900-1998 (Report No. EPA-454/R-00-002). Triangle Park, NC: Author.

Färe, R., Grosskopf, S., Lovell, C. A. K., \& Pasurka, C. (1989). Multilateral productivity comparisons when some outputs are undesirable: A nonparametric approach. Review of Economics and Statistics, 71(1), 90-98.

Färe, R., Grosskopf, S., Norris, M., \& Zhang, Z. (1994). Productivity growth, technical progress, and efficiency change in industrialized countries. American Economic Review, 84, 66-83. 
Fernandez, C., Koop, G., \& Steel, M. F. J. (2002). Multiple-output production with undesirable outputs: An application to nitrogen surplus in agriculture. Journal of the American Statistical Association, 97(458), 432-442.

Gallagher, K. S. (2003, May). Development of cleaner vehicle technology? Foreign direct investment and technology transfer from the United States to China. Paper presented at the United States Society for Ecological Economics 2nd Biennial Meeting, Saratoga Springs, NY.

Hamilton, C., \& Turton, H. (2002). Determinants of emissions growth in OECD countries. Energy Policy, 30, 63-71.

Hamilton, J. D. (1994) Time series analysis. Princeton, NJ: Princeton University Press.

Harbaugh, W., Levinson, A., \& Wilson, D. M. (2002). Reexamining the empirical evidence for an environmental Kuznets curve. Review of Economics and Statistics, 84, 541-551.

Harvey, A. C. (1989). Forecasting, structural time series models, and the Kalman filter. Cambridge, UK: Cambridge University Press.

Harvey, A. C., \& Marshall, P. (1991). Inter-fuel substitution, technical change and the demand for energy in the UK economy. Applied Economics, 23, 1077-1086.

Heil, M. T., \& Selden, T. M. (1999) Panel stationarity with structural breaks: Carbon emissions and GDP. Applied Economics Letters, 6, 223-225.

Heston A., Summers, R., \& Aten, B. (2002). Penn World Table version 6.1. Philadelphia: University of Pennsylvania, Center for International Comparisons.

Hettige, H., Mani, M., \& Wheeler, D. (2000) Industrial pollution in economic development: The environmental Kuznets curve revisited. Journal of Development Economics, 62, 445476.

Hilton, F. G. H., \& Levinson, A. M. (1998). Factoring the environmental Kuznets curve: Evidence from automotive lead emissions. Journal of Environmental Economics and Management, 35, 126-141.

Im, K., Pesaran, M. H., \& Shin, Y. (2003). Testing for unit roots in heterogeneous panels. Journal of Econometrics, 115, 53-74.

International Energy Agency. (2003). Energy balances of OECD countries 2000-2001. Paris: Organisation for Economic Co-operation and Development.

Jiang, T., \& McKibbin, W. J. (2002). Assessment of China's pollution levy system: An equilibrium pollution approach. Environment and Development Economics, 7, 75-105.

Kalman, R. E. (1960). A new approach to linear filtering and prediction problems. Transactions ASME Journal of Basic Engineering, 82, 35-45.

Kander, A., \& Lindmark, M. (in press). Energy consumption, pollutant emissions and growth in the long run: Sweden during 200 years. European Review of Economic History.

Kao, C. (1999). Spurious regression and residual-based tests for cointegration in panel data. Journal of Econometrics, 90, 1-44.

Koop, G. (1998). Carbon dioxide emissions and economic growth: A structural approach. Journal of Applied Statistics, 25, 489-515.

Koop, G., \& Tole, L. (1999). Is there an environmental Kuznets curve for deforestation? Journal of Development Economics, 58, 231-244.

Lansink, A. O., \& Silva, E. (2003). $\mathrm{CO}_{2}$ and energy efficiency of different heating technologies in the Dutch glasshouse industry. Environmental and Resource Economics, 24(4), 395407.

Lefohn, A. S., Husar, J. D., \& Husar, R. B. (1999). Estimating historical anthropogenic global sulfur emission patterns for the period 1850-1990. Atmospheric Environment, 33, 34353444.

Leifman, M., \& Heil, M. T. (2005). Guest editors' note [Special issue]. Journal of Environment $\mathcal{E}$ Development, 14(1), 7-26.

Levy, M. A. (1994). European acid rain: The power of tote board diplomacy. In P. M. Haas, R. O. Keohane, \& M. A. Levy (Eds.), Institutions for the earth: Sources of effective environmental protection (pp. 75-132). Cambridge, MA: MIT Press.

Millimet, D. L., List, J. A., \& Stengos, T. (2003). The environmental Kuznets curve: Real progress or misspecified models? Review of Economics and Statistics, 85, 1038-1047. 
Pedroni, P. (1997). Panel cointegration: Asymptotic and finite sample properties of pooled time series tests with an application to the PPP hypothesis. New results. Unpublished manuscript, Indiana University, Bloomington.

Perman, R., \& Stern, D. I. (2003). Evidence from panel unit root and cointegration tests that the environmental Kuznets curve does not exist. Australian Journal of Agricultural and Resource Economics, 47, 325-347.

Plassmann, F., \& Khanna, N. (2003). A note on 'The simple analytics of the environmental Kuznets curve' (Working Paper No. WP0314). Binghamtom, NY: Binghamton University, Department of Economics.

Reinhard,S., Lovell, C. A. K., \& Thijssen, G. (1999). Econometric estimation of technical and environmental efficiency: An application to Dutch dairy farms. American Journal of Agricultural Economics, 81(1), 44-60.

Selden, T. M., Forrest, A. S., \& Lockhart, J. E. (1999). Analyzing reductions in U.S. air pollution emissions: 1970 to 1990. Land Economics, 75, 1-21.

Stern, D. I. (2002). Explaining changes in global sulfur emissions: An econometric decomposition approach. Ecological Economics, 42, 201-220.

Stern, D. I. (2004a). Diffusion of emissions abating technology. Rensselaer Working Papers in Economics, No. 0420.

Stern, D. I. (2004b). The rise and fall of the environmental Kuznets curve. World Development, 32(8), 1419-1439.

Stern, D. I., \& Common, M. S. (2001). Is there an environmental Kuznets curve for sulfur? Journal of Environmental Economics and Management, 41, 162-178.

Strazicich, M. C., \& List, J. A. (2003). Are $\mathrm{CO}_{2}$ emission levels converging among industrial countries? Environmental and Resource Economics, 24, 263-271.

Streets, D. G., Tsai, N. Y., Akimoto, H., \& Oka, K. (2000). Sulfur dioxide emissions in Asia in the period 1985-1997. Atmospheric Environment, 34, 4413-4424.

United Nations Industrial Development Organization. (various years). Yearbook of industrial statistics. New York: Author.

U.S. Bureau of Mines. (various years). Minerals yearbook. Washington, DC: Author.

Wang, H., \& Wheeler, D. (2003). Equilibrium pollution and economic development in China. Environment and Development Economics, 8, 451-466.

World Bank. (2003). World development indicators 2003. Washington, DC: Author.

Zaim, O., \& Taskin, F. (2000). Environmental efficiency in carbon dioxide emissions in the OECD: A non-parametric approach. Journal of Environmental Management, 58, 95-107.

Zhang, Z. (2000). Decoupling China's carbon emissions increase from economic growth: An economic analysis and policy implications. World Development, 28, 739-752.

Ziegler, J. (1995). Rays of hope in the land of the rising sun. Environmental Health Perspectives, 103(5), 436-441.

David I. Stern received his Ph.D. in geography from Boston University in 1994. He is an associate professor of economics at Rensselaer Polytechnic Institute in Troy, New York. His research interests are in the study of global change and the economics of environment, resources, and development. 